\title{
A critical discourse analysis on newspapers: The case study of nuclear program of Iran
}

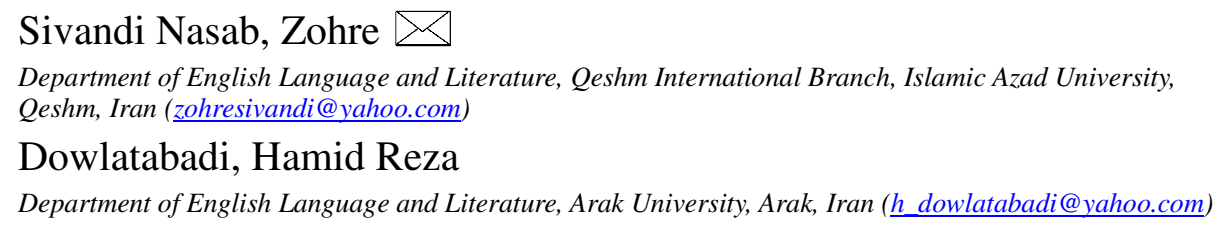

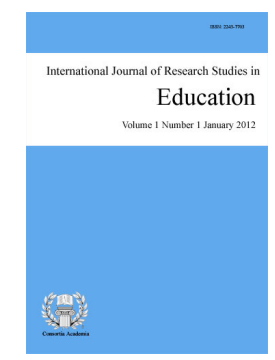

ISSN: $2243-7703$ Online ISSN: 2243-7711

OPEN ACCESS

$\begin{array}{lll}\text { Received: } 16 \text { March } 2015 & \text { Revised: } 5 \text { April 2015 } & \text { Accepted: } 8 \text { May } 2015\end{array}$ Available Online: 15 June $2015 \quad$ DOI: $10.5861 /$ ijrse.2015.1141

\section{Abstract}

This study tried to make a comparative study between two daily English newspapers of Los Angeles Times and Tehran Times in terms of representing negotiations of nuclear program of Iran. To this end, 8 reports in relation to the negotiations of nuclear program of Iran were gathered from the websites of two newspapers which were grouped and analyzed in terms of the utilized discursive strategies resorting to the discursive micro and macro-strategies suggested by Van Dijk (2000). In order to have more dependable results, the gathered data was numerated and tabulated. The results of the study showed that the Los Angeles Times tended to utilize the Authoritative, Explanation, Evidentiality and Counterfactual discursive strategies; whereas, the Tehran Times utilized the Actor Description, Hyperbole, Lexicalization, Repetition and Situation Description discursive strategies.

Keywords: critical discourse analysis; discursive strategies; ideology; micro-strategies; macro-strategies 


\section{A critical discourse analysis on newspapers: The case study of nuclear program of Iran}

\section{Introduction}

Newspaper discourse has recently been the focus of many critical discourse analysts to reveal the biased language and raise the reader's consciousness of the way through which the language is manipulated. Considering the fact that few study, if any, tried to compare the discourses of Los Angeles Times and Tehran Times in representing the negotiations of nuclear program of Iran utilizing the tenets of critical discourse analysis; the researcher tried to see whether there is any bias in the language of these newspapers speaking in the case of Iran's nuclear program negotiations in order to reveal how opposing ideologies are represented differently in these newspapers.

Admittedly, the newspapers, according to critical discourse analysis perspective, depict different events and phenomena based on political and social perspectives. It means that the mass media are embedded with hidden ideologies and manipulated discourse structures. Critical discourse analysis, in Gee's (2004, pp. 32-33) view is "an approach to language analysis that considers texts as parts of specific social practices that have political implications about issues of status, solidarity, and of distribution of social goods and power". In fact, "CDA examines how texts represent and construct reality within a specific ideological system through implicit messages based on what is said and left unsaid" (Heros, 2009, p. 173).

It is evident that a number of language and discourses are transmitting to people through diverse types of media like internet, television, newspapers, adverting or radio broadcast among which the role of newspapers in ideological manipulation is prominent. Effectively, Fowler (1991) assumes that newspapers are not neutral in covering diverse events based on the viewpoints followed by them. The aforementioned issues were some incentives for conducting a study to reveal the differences between Los Angeles Times and Tehran Times in depicting the negotiations of nuclear program of Iran in order to determine the ideological differences between the two newspapers.

\subsection{Significance of the Study}

Newspapers particularly comprise significant resources for language teaching because of their authentic nature; it seems that the domain of education needs to make an investigation on the way social issues are depicted in the newspaper in order to reveal different perspectives and outlooks through which negotiations on Iran's nuclear program are constructed to raise the consciousness of students about the manipulated and hidden meaning of any text-written or spoken.

\section{Review of Literature}

Language as a social practice involves multifaceted and complicated social issues. Hence, different events may be represented ideologically in the media in general and newspapers in particular. There is no doubt that investigating some authentic sources like newspapers is beneficial in depicting the ideological manifestations of the phenomena. In effect, some background knowledge is represented in this section to clarify the foundations of this study.

\subsection{Discourse Analysis: Theoretical Definitions}

Discourse is differently defined by different researchers based on the context in which it is applied. Van Dijk (1997) considers discourse as a form of spoken language (e.g. what is presented in lectures, the ideas of certain schools of thoughts like contemporary philosophies). Hence, Van Dijk (1998) emphasizes that the concept of discourse indicates to a particular way of language in which discourse sheds light on language use and social 
A critical discourse analysis on newspapers: The case study of nuclear program of Iran

interaction in communication (e.g. interviews, conversations, meetings, letters, diaries, propaganda, discussions, laws, contracts, political discourses, songs, poetry, and news).

Discourse, for Van Dijk (1997), involves social matters through which language is utilized for communication and also expressing feelings, ideas, and beliefs. Wodak and Meyer (2001), in a similar vein, argue about three orientations for discourse, i.e. the German and Central European tradition (GCET), the Anglo-American tradition (AAT), and the Foucauldian tradition (FT). They continued that GCET views discourse as text linguistics; AAT as written and oral texts; FT as knowledge, cognition and emotions. In addition, Van Dijk (1998), fragments of situation models and relevant information of communicative situations are fundamental. Besides to the relevant information, socially shared knowledge and beliefs seem to be crucial in dealing with discourse for Van Dijk (1998). Van Dijk (1998) argues about the social dimensions which are deployed through verbal or non-verbal interaction as the crucial elements for cognitive processes.

The second element Van Dijk (1997) illustrates in dealing with discourse is the social dimension which clarifies the relationship between language and society. Van Dijk (1998) considers language as influential factor for society through which people's identities, their cultural group, or communities are constructed besides. Ideology demands shared knowledge, communal interests and individual practices through which the members of any group or society, what they do and why they do in that way, their norms for goodness and badness as well as their social positions are determined (Van Dijk, 1997). Van Dijk (1998) emphasizes that any social group have its particular way to interpreter, comprehend, and classify different phenomena.

\subsection{Van Dijk's Model}

Van Dijk (2000) has introduced his well-known Socio-Cognitive model which is a model to CDA which is based on the interconnection among cognition, discourse and society. Van Dijk's model especially is beneficial for analyzing the newspapers for stereotypes as well as biases on ethnicity. Van Dijk (2000) has introduced a theoretical model for analyzing ideological discourse. Van Dijk (1998) argues that his model is able to deal with the ideology-laden issues since a socio-cognitive approach "is able to explain how ideologies monitor practices of social actors in the society" (p. 23). Van Dijk's (2000) model also considers discourses to clarify eth roles of ideologies through which texts and talks are constructed, of processes participants go through in understanding ideological discourse and of the ways discourse may be manipulated to construct ideologies. In revealing the ideology which is covered in a text, Van Dijk (2000) recommends analyzing the discursive structures utilized in a text.

\subsection{Some Empirical Studies}

The past two decades witnessed an interest into the potentials of critical discourse analysis to investigate news articles. Mahfouz (2013), for example, investigated the police news story framing in two Egyptian newspapers of Al-Gomhuria and Al-Dostour before January 25 revolution. To this end, the ideological perspectives of the two newspapers were explored resorting to critical discourse analysis framework. The results of the study showed that the two newspapers manipulated the language to be in harmony "with the beliefs held by the two newspaper's target audiences" (Mahfouz, 2013, p. 309).

Ghannam (2012) made an investigation on six Lebanese newspapers in order to determine whether "the ideology behind the text limits the freedom of expression of the newspaper in question" (p. iii) and to what extent. To this end, "the transitivity of the sentences, the active and passive voice used in the articles, the modality with the help of modal auxiliary verbs, disjuncts or modal adjectives" were investigated in the selected articles. The study showed that different newspapers have deployed diverse and opposing political ideologies through manipulating language. Ghannam (2012) argues that language is an instrument which is purposely manipulated to meet the hidden interpretation the newspapers expect.

Donkin (2012) investigated eleven major state online newspapers in terms of the portrayals of the National 
Sivandi Nasab, Z., \& Dowlatabadi, H. R.

School Chaplaincy Program. To this end, she selected and adopted Fairclough's three-dimensional model and the selected articles were analyzed in terms of assumptions (Existential, Propositional and Value) to determine the ways through which language is used to construct ideologies and discourses about the Chaplaincy Program. Effectively, Donkin (2012) mad a comparative study on the role of chaplains, the use of government funding for the Program, as well as church and state boundaries during 2006, 2007 and 2011. It was found that the articles in 2006 and 2007 depicted "a more positive representation of the Chaplaincy Program and, in 2011 the Program was portrayed more negatively due to considerable support for the High Court Challenge" (p. iii). Hence, she showed that "online newspaper portrayals of the Chaplaincy Program are predominantly biased based upon the assumptions made by journalists, and the people they choose to represent in their news articles" (p. iii).

Teo (2012) studied two Australian newspapers in terms of racism. To this end, The Sydney Morning Herald and The Daily Telegraph were selected as the two Australian newspapers to be investigated in terms of racism utilizing a critical discourse analysis framework. Teo (2012) concluded that two newspapers utilize "systematic 'othering' and stereotyping of the ethnic community by the 'white' majority" (Teo, 2012, p. 657). Hence, the results of the study showed that the two newspapers "reflect and reinforce the marginalization of recent Vietnamese migrants into Australia" (Teo, 2012, p. 657).

\section{Methodology}

\subsection{Corpus of the study}

In conducting the present study the corpus was gathered from the websites of Los Angeles Times and Tehran Times from which the articles covered the news of negotiations on Iran's nuclear program were selected during one month.

\section{Tehran Times' Headlines}

$>$ Obama's flip-flop destroys trust: Zarif

$>$ Ashton says she wants 'best possible atmosphere' for Iran nuclear talks

$>$ Claim of arrest of Iranian spy shows Israel's desperation: official

$>\quad$ Iran's right to enrichment non-negotiable: Rouhani

\section{Los Angeles Times' Headlines}

U.S. not being 'played' by Iran on nuclear issue, Kerry insists

$>\quad$ Iran foreign minister talks conciliation, calls for end to sanctions

$>\quad$ Netanyahu heads to U.S. to 'tell the truth' on Iran

$>$ The Sunday morning front pages in Iran told the story of how the first tentative signs of a thaw in U.S.-Iranian relations are seen in the Islamic republic

\subsection{Procedures}

The following steps were taken in conducting the present study:

$>$ Gathering news articles from the two newspapers of Tehran Times and Los Angeles Times which covered negotiations on Iran's nuclear program;

$>$ Analyzing them; 
$>$ Classifying different paragraphs of the articles based on the both macro- and micro-strategies;

$>\quad$ Numerating the utilized micro- and macro-strategies;

$>\quad$ Tabulating the gathered data;

$>$ Describing the data

$>$ Answering the raised question

\section{Results}

In this part, the results are illustrated in order to provide some bases for discussion. We had two articles-one from Tehran Times and one from the Los Angeles Times with similar themes. Tehran Times has selected the headline "Obama's flip-flop destroys trust: Zarif" and the Los Angeles Times the headline "U.S. not being 'played' by Iran on nuclear issue, Kerry insists". Considering the two headlines, which are from the two opposite newspapers, illustrates that the two headlines try to accuse the behavior of the other side, for example, Tehran Times insists on the fact that Obama is changing his mind each time; whereas the headline of the Los Angeles Times stresses on the deceptive characteristic of Iran. Effectively, the two headlines have resorted to the macro discursive strategies of positive-self representation and negative-other representation.

The first four paragraphs emphasize, in effect, on the inconsistency of the USA in terms of behaviors, claims and statements. Effectively, these paragraphs have utilized a number of discursive strategies, i.e. Counterfactuals (meaning, argumentation), Disclaimer (meaning), and Explanation (meaning, argumentation). For example when the report says "The Iranian foreign minister has said that the U.S. President Barack Obama's flip-flop threatens efforts to build trust", it is utilizing Disclaimer (meaning) discursive strategy.

The next paragraph, i.e. the fifth one, highlights the role of Israel on the disrupting relations between Iran and USA as the paragraph says "during his meeting with Israeli Prime Minister Benjamin Netanyahu on Monday, Obama said, "We take no options off the table, including military options, in terms of making sure that we do not have nuclear weapons in Iran”. Effectively, the paragraph has utilized the Interaction and context discursive strategy. The rest of the report is devoted to the discussion about Israel and Netanyahu. These paragraphs have resorted to the Lexicalization (style), Semantic macro-strategy, and lexicalization along with the other-negative representation in which Israel is accused.

The Los Angeles Times' report was started by positive-self representation of US and negative-other representation of Iran in which Iran is accused of being untrustworthiness. Hence, this paragraph has utilized Hyperbole (Rhetoric), Implication (meaning) and Negative Other-presentation (Semantic macro-strategy) discursive strategies when it says US would never allow itself to be "played" in which played is emphasized and highlighted. The next paragraph which is a supporting paragraph provides some detail regarding the issue. Effectively, this paragraph has utilized Actor description (meaning) when it says Defense Secretary Chuck Hagel, as well as Explanation (meaning, argumentation), and Situation description (meaning) discursive strategies when it says " met with reporters in Tokyo on the first stop of an Asian tour and cast the soon-to-resume negotiations with Tehran as an opportunity for peaceful resolution of a long and bitter standoff over Iran's suspected pursuit of nuclear weapons".

The third paragraph has utilized the discursive strategies of Situation description (meaning) by stating "vowed in his speech to the U.N. General Assembly last week", Fallacies (argumentation) when mentions "aimed at anything other than civilian uses such as power generation and medical research" as well as explanation discursive strategies by illustrating "that his sanctions-battered nation is eager to put Western concerns to rest that Tehran's nuclear developments". Effectively, the paragraph is designed in such a way that Iran is convicted of being slyness. 
The fourth and fifth paragraphs are designed in supporting the third paragraph. In effect, the fourth and fifth paragraphs heavily relied on the explanation discursive strategy (e.g. the pledge from Rouhani that Iran will never build nuclear weapons) along with the Evidentiality (meaning, argumentation) one (e.g. that has been hostile since the 1979 Islamic Revolution and the hostage-taking episode that followed at the U.S. Embassy in Tehran).

The sixth paragraph started with topicalization in which Iran is accused of being untrustworthiness when it states "but Iran's changing diplomatic posture was met on Tuesday with deep skepticism". In effect, this paragraph is dealing with the Israel's role in the negotiation between Iran and USA. In other words, this paragraph has resorted to the Interaction and context, Lexicalization (style), as well as Negative Other-presentation (Semantic macro-strategy).

The other paragraphs also provide further details regarding the nuclear program negotiation between the two countries. In these paragraphs, a number of discursive strategies are utilized, i.e. Actor description (meaning), Burden (topos), Explanation (meaning, argumentation) as well as Fallacies (argumentation).

The next headline was "The Sunday morning front pages in Iran told the story of how the first tentative signs of a thaw in U.S.-Iranian relations are seen in the Islamic republic" which is a tentative headline is from Los Angeles Times. In fact, this headline is designed in such a way that highlights the desires of Iran to improve its relations with the USA. Hence, the headline is heavily resorted to the Irony (rhetoric) discursive strategy.

The report provides, in effect, some comments and interpretation of the future relations between the two countries. The report, for example, utilizing Comparison (meaning, argumentation) discursive strategy in this sentence "as in the United States, different factions are viewing the developments very differently" tries to develop its discussion. Furthermore, this report numerates some different viewpoints by using Example/Illustration (argumentation) discursive strategy as in the following paragraph:

The daily newspaper Shargh (Orient), which is considered aligned to reformist forces, ran a front-page photo of angry students punching the air and beating the window of the car containing President Hassan Rouhani on his return from the United States.

It should be also considered that this report heavily relied on the Evidentiality (meaning, argumentation), Authority (argumentation) when mentions Hashemi Rafsanjani as well as Example/lllustration (argumentation) (e.g. Different reactions to phone calls and meeting in New York in domestic and foreign media continue) as in the following paragraph extracted from this report:

Hamshahri, aligned with Tehran's municipality, carried a relatively neutral headline: "Different reactions to phone calls and meeting in New York in domestic and foreign media continue." And, wrote the daily newspaper Arman, which is considered aligned with former President Hashemi Rafsanjani: "Do not hastily judge the results of the trip to New York."

The next report from the Tehran Times which was published on October, 3, 2013 with the headline of "Iran's right to enrichment non-negotiable: Rouhani". In effect, the headline has resorted to the Presupposition (meaning) discursive strategy to determine the limits of the negation between the two countries. The lead paragraph is in line with the headline in which a restatement with more information is provided.

"The people should be assured that the right to nuclear technology and the right to enrichment in Iran are not negotiable," Rouhani told reporters after a cabinet meeting on Wednesday when asked about U.S. Secretary of State John Kerry's recent remarks in which he said the sanctions could be eased if Iran took certain measures, including signing the additional protocol to the NPT and reducing the level of its uranium enrichment.

The lead paragraph has utilized the situation description, presupposition, as well as explanation discursive strategies. The next paragraph also supports the lead paragraph which indicated the Lexicalization (style), and 
Repetition (rhetoric) discursive strategies.

"We hold negotiations on details, but we never regard our principles as negotiable," Rouhani stated. "Based on our principles, we have opened up the doors of our nuclear sites to the International Atomic Energy Agency and they can have supervision," he added.

Other paragraphs also provide some detail regarding the issue in which History as lesson (topos), Implication (meaning) as well as explanation discursive strategies are utilized. Tehran Times has also selected the headline "Ashton says she wants 'best possible atmosphere' for Iran nuclear talks" utilizing the Authority (argumentation) discursive strategy. This article was published on October, 1, 2013. The following is the lead paragraph of the report:

A top EU official, asked if new sanctions should be imposed on Iran as talks about its nuclear program unfold, said she wanted to go to the October 15-16 talks with Iran in Geneva with "the best possible atmosphere," Reuters reported on Monday.

The lead paragraph has utilized the Authority (argumentation) discursive strategy when it says "A top EU official". The rest of the report which supports the lead paragraph heavily relies on Authority (argumentation), Explanation (meaning, argumentation), and Interaction and context discursive strategies. For example in all the paragraphs, it is stated that "EU foreign policy Chief Catherine Ashton said" which is an example of Authority (argumentation) discursive strategy. Furthermore, all the paragraphs are, in effect, an interaction between the reporter and Ashton which highlights the Interaction and context discursive strategy.

The Los Angeles Times selected the headline "Iran foreign minister talks conciliation, calls for end to sanctions". This article was published on September, 29, 2013. This headline is resorting to the lexicalization when it states "conciliation, calls for end to sanctions". The lead paragraph is as follows:

Iran's foreign minister said Sunday that his country was willing to negotiate with the United States over its nuclear program but that Washington needed to reciprocate by stopping the sanctions that have crippled Iran's economy.

The lead paragraph has utilized the Counterfactuals (meaning, argumentation) discursive strategy when it states "Iran's foreign minister said Sunday that his country was willing to negotiate with the United States over its nuclear program but that Washington needed".

The next paragraph has resorted to the hyperbole, and Disclaimer (meaning) discursive strategy when it implicitly numerates the positive-self representation as well as negative-other representation. For example, there is hyperbole discursive strategy in the statement of "the U.S. and Iran had taken the "first step in removing the tensions, doubts and misgivings that the two sides have had about each other for the last 30-some years". Furthermore, the report has utilized topicalization when it states "Taking a tone that was conciliatory at times but mainly tough, Mohammad Javad Zarif said".

The third paragraph shows the Pre-supposition discursive strategy when it mentions "Speaking in fluent English, the American-educated Zarif also insisted that Iranian officials do not believe the Holocaust is a myth". The rest of the report, in the similar vein, utilized a number of discursive strategies like Hyperbole, Context and interaction or Explanation and Evidentiality. Finally, the report is ended by some comments extracted from Israel and Netanyahu. Effectively, the last part has utilized the History discursive strategy. The last selected article from the Tehran Times had the headline of "Claim of arrest of Iranian spy shows Israel's desperation: official" which was published on October, 1, 2013. The headline has utilized the Disclaimer (meaning) strategy .The following is the lead paragraph of the report:

Israel's recent announcement that it had arrested a spy who is allegedly connected to Iran was a desperate effort to get out of isolation, an Iranian Foreign Ministry official said on Tuesday. 
The lead paragraph is, effectively, resorted to the Explanation (meaning, argumentation) discursive strategy when it provides a reason for Israel's claim. The next paragraph has utilized the Authority (argumentation) discursive strategy when it refers to "Foreign Ministry spokeswoman Marzieh Afkham said". The paragraph also shows the Negative-other representation when mentions "The Zionist regime" or when says "hawkish rhetoric against Iran". Furthermore, the paragraph has utilized the pre-supposition discursive strategy when says "repetitive scenarios". The last part of the report using intertextuality tries to provide some background for better understanding of the speeches stated by Foreign Ministry spokeswoman Marzieh Afkham. Effectively, the last part of the report has deployed History as lesson (topics) discursive strategy as in the following paragraph:

As Israeli Prime Minister Benjamin Netanyahu flew on Sunday to the United States for a visit focused on Iran's nuclear program, Israel's Shin Bet security service announced that Ali Mansouri had been arrested on September 11 on suspicion of spying for the Islamic Revolution Guards Corps (IRGC), according to Reuters.

The Los Angeles Times, in a similar vein, utilized a topic on Israel and its influence on the process of relations between Iran and the USA and improvement in their relations which had the headline of "Netanyahu heads to U.S. to 'tell the truth' on Iran". The headline was designed in such a way in which negative-other representation was utilized about Iran and its purposes. The following is the lead paragraph of this report:

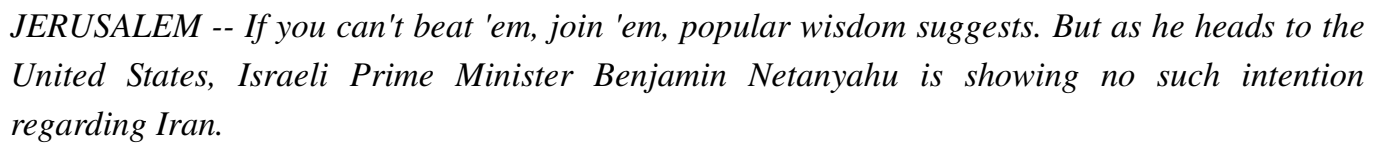

The lead paragraph is started with Irony (rhetoric) discursive strategy through the expression "If you can't beat 'em, join 'em, popular wisdom suggests". Furthermore, the paragraph has deployed the Counterfactuals (meaning, argumentation) discursive strategy when it states Israeli Prime Minister Benjamin Netanyahu is showing no such intention regarding Iran". The next paragraphs utilizing the Explanation discursive strategy supports the lead paragraph and provide the details of the topic of the report. The last paragraphs also provide comments and re-emphasize on the aforementioned issues. Hence, these paragraphs have used the Explanation, Repetition, and Authority (argumentation) as well as Situation description discursive strategies are utilized as in the following paragraph:

Speaking in a radio interview, Landau pointed to the International Atomic Energy Agency's last report of 1,000 new centrifuges being introduced at the Iranian facility at Natanz. These can enrich uranium up to five times faster than the older ones, suggesting Iran could enrich.

In order to have a better understanding of the results of analyzing the two newspapers of Tehran Times and Los Angeles Times regarding the utilized discursive strategies, the frequency and types of the utilized discursive strategies were summarized in table 1 .

The table illustrates that the reports in Tehran Times have utilized 217 different cases of discursive strategies while Los Angeles Times showed 278 cases. The results in the table shows that the Situation description was the most utilized discursive strategy in Tehran Times; whereas, Irony was the least utilized discursive strategy. Furthermore, the Los Angeles Times shows that Authoritative discursive strategy was the most dominant and the Evidentiality was the least one. To have more comprehensive picture of the similarities and differences between the two newspapers, the data are presented in Figure 1.

The figure shows that the two newspapers have different direction in deploying different discursive strategies in which the differences between the discursive strategies of Authoritative, Actor Description, Hyperbole, Explanation and Evidentiality are vast. The Following section deals with discussion to provide some bases for answering the question. 
Table 1

Frequency and Type of Discursive Strategies in Newspapers: Tehran Times vs. Los Angeles Times

\begin{tabular}{llcc}
\hline \multirow{2}{*}{ Discursive Strategies } & \multicolumn{2}{c}{ Newspapers } \\
\cline { 3 - 4 } & & Tehran Times & Los Angeles Times \\
\hline 1 & Actor Description & 21 & 16 \\
2 & Hyperbole & 31 & 15 \\
3 & Explanation & 19 & 35 \\
4 & History as Lesson & 11 & 11 \\
5 & Authoritative & 11 & 60 \\
6 & Lexicalization & 14 & 9 \\
7 & Repetition & 15 & 11 \\
8 & Presupposition & 12 & 13 \\
9 & Irony & 4 & 11 \\
10 & Disclaimer & 10 & 10 \\
11 & Context and Interaction & 16 & 16 \\
12 & Counterfactual & 11 & 13 \\
13 & Situation description & 42 & 39 \\
14 & Evidentiality & - & 6 \\
15 & Total & 217 & 278 \\
\hline
\end{tabular}

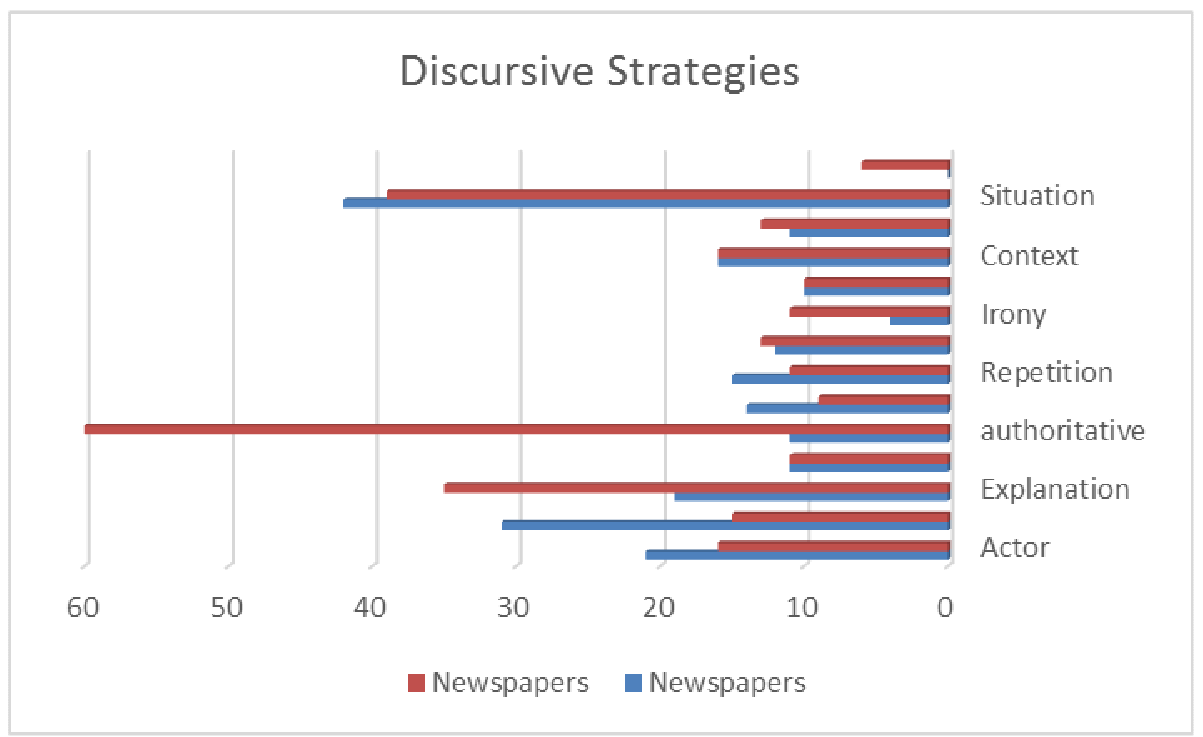

Figure 1. Frequency and Type of Discursive Strategies in Newspapers: Tehran Times vs. Los Angeles Times

\section{Discussion and Conclusions}

This study was an attempt to make a comparative study between two daily English newspapers of Los Angeles Times and Tehran Times in terms of representing negotiations of nuclear program of Iran. To this end, a number of articles in relation to this subject were gathered from the websites of the two newspapers and were analyzed which resulted into some differences. Effectively, it was revealed that the two newspapers represent the Disclaimer (meaning) strategy. In fact, the two newspapers try to represent their own perspective positively and others negatively. In other words, the Los Angeles Times depicted the politics and behaviors of the United States of America as well as Israel positively; whereas, this newspaper published its articles in such a way that Iran's intention is deceitful and dishonest. Furthermore, Tehran Times, in a similar vein, depicts Iran's intention and politics as the honest one; whereas, this is the USA that shows flip-flop behaviors.

It was also revealed that the Los Angeles Times heavily relied on Authoritative, Explanation, Evidentiality and Counterfactual discursive strategies. Furthermore, it was found that Tehran Times has dominantly utilized Actor Description, Hyperbole, Lexicalization, Repetition and Situation Description discursive strategies. Hence, the results of the study are in harmony with Mahfouz (2013, p. 309) in which the reports are developed "with the 
Sivandi Nasab, Z., \& Dowlatabadi, H. R.

beliefs held by the two newspaper's target audiences".

The findings of this study also support Ghannam's (2012) findings which emphasize that different newspapers have deployed diverse and opposing political ideologies through manipulating language. Hence, language is an instrument which is purposely manipulated to meet the hidden interpretation the newspaper expect. In addition, the results of the study highlight the significance of teaching news and newspapers' articles. Hence, the findings of the study are in harmony with Fowler's (1991, p. 10) argument that "institutions of news reporting and presentation are socially, economically and politically situated, all news is always reported from some particular angle. The structure of the medium encodes significances which derive from the respective positions within society of the publishing or broadcasting organizations".

In effect, the two newspapers have utilized self-positive representation and negative-other representation based on their ideological perspectives. More generally, the findings of this study corroborate earlier findings of Koosha and Shams (2005), Ghiasian (2006), KhosraviNik (2008), Atai and Adriani (2009), and Yaghoobi (2009), among many other studies conducted in a CDA framework, about the biased representation of events and social groups in newspapers. The results of this study also lend supports to van Dijk's (2000) belief that "discourses express, confirm, instantiate or constitute ideologies" (p. 86) and to the fact that ideologies are injected in discourse by the use of different kinds of discursive strategies like the ones which are included in van Dijk's (2000) framework.

\subsection{Pedagogical Implications}

The first pedagogical implication of this study is related to the consciousness-raising which according to Fairclough (2001) is the main goal of CDA. Effectively, the students need to be aware of the role played by manipulating language in molding the worldview of students regarding the issues, the people, and the world around them. In fact, students' raised awareness regarding using language is fundamental for EFL learners since they face with a vast variety of materials which follow pre-determined perspectives. Hence, EFL students need to "act as transmitters of foreign thoughts and beliefs to their own culture" (Koupaee, 2010, p.1). Effectively, it is crucial for EFL students to be aware of the covert meanings and ideologies which are hidden in the materials and which are penetrating into their minds unconsciously.

The findings of this study are also beneficial with the journalism courses. In fact, the EFL teachers of these courses can utilize the principles of critical discourse analysis framework in teaching journalism courses to equip their students to critically analyze the news reports they expose to. Moreover, the results of this study are insightful for improving the students' reading skills of EFL students (Asgharzadeh, 2009). The issue should not be ignored that the results of the study has also implication for EFL contexts for increasing the creativity, motivation and activity of EFL students (Koupaee, 2010). Rahimi and Sahragard (2007) point out that "second language learning will doubtless be a debacle or a distressingly frustrating experience unless the intricate cultural pragmatic constraints on communication, reading and writing are brought to the limelight" (p. 134). Another implication of the present study is related to the critical thinking and critical language awareness of EFL students. Utilizing the principles of CDA, the students are capable to explore the world around them more critically in order not to take everything for granted and make questions regarding the raised issues.

\section{References}

Asgharzadeh, R. (2009). The effect of teaching critical reading through critical discourse analysis on high school EFL learners' reading comprehension. Unpublished master's thesis, University of Shiraz, Shiraz, Iran.

Atai, M. \& Adriani, H. (2009). On the representation of Iran's post-resolution nuclear issues in American news editorials: A critical discourse analysis. Iranian EFL Journal, 5, 20-45.

Chilton, P. (2004). Analyzing political discourse: Theory and Practice. NY: Routledge. 
A critical discourse analysis on newspapers: The case study of nuclear program of Iran

Donkin, A. (2012). Australian national school chaplaincy program: A critical discourse analysis of online newspaper portrayals. Unpublished BA thesis, Edith Cowan University, Perth, Australia.

Fairclough. (2001). Language and power. Longman. London.

Fowler, R. (1991). Language in the news: Discourse and ideology in the press. London: Routledge.

Gee, J. P. (1999). An introduction to discourse analysis: Theory and method. NY: Routledge

Gee, J. P. (2004). Discourse analysis: What makes it critical? In R. Rogers (Ed.), Critical discourse analysis in education (pp. 19-50). New Jersey/London: Erlbaum Associates Publishers.

Ghannam, N. (2012). Newspaper ideology: A critical discourse analysis of an event published in six Lebanese newspapers. Unpublished Masteral thesis, University of the Witwatersrand, South Africa. Retrieved from

http://wiredspace.wits.ac.za/bitstream/handle/10539/11267/NADA\%20FINAL\%20checked\%20by\%20J Inggs.pdf?sequence $=1$

Ghiasian, M. (2006). The representation of Muslims in American and British newspapers before and after September 11. Unpublished Masteral thesis, Tarbiat Modarres University, Tehran, Iran.

Heros, S. (2009). Linguistic pluralism or prescriptivism? A CDA of language ideologies in Talento, Peru's official textbook for the first-year of high school. Linguistics and Education, 20, 172-199. http://dx.doi.org/10.1016/j.linged.2009.01.007

KhosraviNik, M. (2008). The British newspapers and the representation of refuges, asylum seekers and immigrants between 1996 and 2006. Retrieved from http://www.ling.lancs.ac.uk/groip/clsl/docs/clc128.pdf

Koosha, M., \& Shams, M., R. (2005). A critical discourse study of news discourse: Iran's Nuclear Issues in the British newspapers. IJAL, 8(2), 107-141.

Koupaee, D. Z. (2010). Teaching reading with a critical attitude: Using critical discourse analysis (CDA) to raise EFL university students' critical language awareness (CLA). Unpublished masteral thesis, University of Kashan, Kashan, Iran.

Mahfouz, A. R. (2013). A critical discourse analysis of the police news story framing in two Egyptian newspapers before January 25 revolution. European Scientific Journal, 9(8), 309-332.

Rahimi, A., \& Sahragard, R. (2007). Critical discourse analysis. Tehran: Jungle Publications.

Teo, P. (2000). Racism in the news: a critical discourse analysis of news reporting in two Australian newspapers. Discourse Society, 11(7), 7-49. http://dx.doi.org/10.1177/0957926500011001002

Van Dijk, T. A. (1997). The study of discourse. In T. A. Van Dijk (Ed.), Discourse as structure and process (Vol. 1, pp. 1-35). London: Sage. http://dx.doi.org/10.4135/9781446221884.n1

Van Dijk, T. A. (1998). Ideology: A multidisciplinary study. London. Sage Publications.

Van Dijk, T. A. (2000). Ideology and discourse: A multidisciplinary introduction. London: Routledge.

Van Dijk, T. A. (2001). Multidisciplinary CDA: A plea for diversity. In R. Wodak \& M. Meyer (Eds.), Methods of critical discourse analysis (pp. 95-120). London: Sage. http://dx.doi.org/10.4135/9780857028020.d7

Wodak, R. (2001). What CDA is about: A summary of its history, important concepts and its developments. In R. Wodak \& M. Meyer (Eds.), Methods of critical discourse analysis (pp. 1-13). London: Sage Publications. http://dx.doi.org/10.4135/9780857028020.n1

Yaghoobi, M. (2009). A critical discourse analysis of the selected Iranian and American printed media on the representations of Hizbullah-Israel war. Journal of Intercultural Communication, 21, 124-15. 
Sivandi Nasab, Z., \& Dowlatabadi, H. R. 